\title{
Corrigendum: Interactive Brain Activity: Review and Progress on EEG-Based Hyperscanning in Social Interactions
}

\begin{abstract}
Difei Liu ${ }^{1,2+}$, Shen Liu ${ }^{1 *+}$, Xiaoming Liu ${ }^{1,3}$, Chong Zhang ${ }^{4}$, Aosika Li ${ }^{5}$, Chenggong Jin ${ }^{6}$, Yijun Chen ${ }^{7}$, Hangwei Wang ${ }^{6}$ and Xiaochu Zhang ${ }^{1,6,8,9 *}$

${ }^{1}$ School of Humanities and Social Science, University of Science and Technology of China, Hefei, China, ${ }^{2}$ Department of Education, Hefei University, Hefei, China, ${ }^{3}$ School of Foreign Languages, Anhui Jianzhu University, Hefei, China, ${ }^{4}$ Department of Mechanical and Automation Engineering, The Chinese University of Hong Kong, Hong Kong, China, ${ }^{5}$ Department of Social and Behavioural Sciences, City University of Hong Kong, Hong Kong, China, ${ }^{6}$ CAS Key Laboratory of Brain Function and Disease, and School of Life Sciences, University of Science and Technology of China, Hefei, China, ${ }^{7}$ School of Chemistry and Materials Science, University of Science and Technology of China, Hefei, China, ${ }^{8}$ Hefei Medical Research Center on Alcohol Addiction, Anhui Mental Health Center, Hefei, China, ${ }^{9}$ Academy of Psychology and Behavior, Tianjin Normal University, Tianjin, China
\end{abstract}

Keywords: social interaction, EEG-based hyperscanning, inter-brain synchrony, phase coherence, inter-brain activities

\section{A Corrigendum on}

Interactive Brain Activity: Review and Progress on EEG-Based Hyperscanning in Social Interactions

by Liu, D., Liu, S., Liu, X., Zhang, C., Li, A., Jin, C., et al. (2018). Front. Psychol. 9:1862. doi: $10.3389 /$ fpsyg.2018.01862

tThese authors have contributed equally to this work and shared first authorship

Specialty section: This article was submitted to Evolutionary Psychology, a section of the journal Frontiers in Psychology

Received: 17 March 2021 Accepted: 18 March 2021

Published: 07 May 2021

Citation:

Liu D, Liu S, Liu X, Zhang C, Li A, Jin $C$, Chen $Y$, Wang $H$ and Zhang $X$ (2021) Corrigendum: Interactive Brain

Activity: Review and Progress on EEG-Based Hyperscanning in Social Interactions.

Front. Psychol. 12:681900. doi: $10.3389 /$ fpsyg.2021.681900
In the original article, we neglected to include the funder Humanities and Social Science Project of Hefei University, 18RW12ZDA, to Difei Liu. The updated Acknowledgments section is shown below.

\section{ACKNOWLEDGMENTS}

This work was supported by grants from Humanities and Social Science Project of Hefei University (18RW12ZDA), the National Key Basic Research Program (2016YFA0400900, 2018YFC0831101), the National Natural Science Foundation of China (31471071, 31771221, 61773360, and 71874170), and the Fundamental Research Funds for the Central Universities of China.

The authors apologize for this error and state that this does not change the scientific conclusions of the article in any way. The original article has been updated.

Copyright $\odot 2021 \mathrm{Liu}, \mathrm{Liu}, \mathrm{Liu}$, Zhang, Li, Jin, Chen, Wang and Zhang. This is an open-access article distributed under the terms of the Creative Commons Attribution License (CC BY). The use, distribution or reproduction in other forums is permitted, provided the original author(s) and the copyright owner(s) are credited and that the original publication in this journal is cited, in accordance with accepted academic practice. No use, distribution or reproduction is permitted which does not comply with these terms. 